\title{
Tudo Por Recomeçar (PQ'15) / Triz: a grafia da espada do tempo
}

\author{
Doris Rollemberg Cruz \\ Universidade Federal do Estado do Rio de Janeiro - UNIRIO, Rio de Janeiro/RJ, Brasil \\ E-mail: dorisrollemberg@uol.com.br
}

\section{Resumo}

O texto é parte integrante da pesquisa de pós-doutoramento Grafismos na solidão, desenvolvida na Faculdade de Arquitetura da Universidade de Lisboa. $\mathrm{O}$ assunto nuclear da investigação procura identificar o locus solus, entendido como espaço utópico construído solitariamente para sonhar com a criação da obra concentrada em seu próprio processo criativo. $O$ estudo redesenha os conceitos primeiramente traçados na tese A cenografia além do espaço e do tempo. O Teatro de dimensões adicionais. Para tal, volta-se à criação da maquete-objeto Grafismos, exposta na Mostra World Stage Design de 2013. O atual interesse ao retomar a obra Grafismos é pensar o modelo reduzido como objeto em si, como obra original que se torna autônoma, tendo sido criada a partir de outra obra de origem. A pesquisa estuda ainda outras obras que pertencem ao espaço da solidão. Resultantes criadas em outro formato, objetivando grafar a travessia do próprio espaço temporal. Para refletir sobre a obra autônoma derivativa de outra composição, foi escolhida a obra esférica Triz de Freusa Zechmeister, exposta na Representação Brasileira da Quadrienal de Praga 2015 Tudo por recomeçar.

\section{Palavras-chave}

Artes. Cenografia. Modelo reduzido. Quadrienal de Praga 2015. Freusa Zechmeister. Grupo Corpo.
The text is an integral part of the postdoctoral research Grafismos na solidão, developed at the Faculty of Architecture of the University of Lisbon. The nuclear subject of research seeks to identify the locus solus, understood as utopian space built solely so that it can devote itself to dreaming of the creation of the work concentrated in its own creative process. The research redesigns the concepts first traced in the thesis The scenography beyond space and time. The Theater of additional dimensions. To this end, the research returns to the creation of the model-object Grafismos exhibited at the World Stage Design Exhibition 2013. The current interest in resuming to the Grafismos is to think of the reduced model as an object itself, as an original work that becomes autonomous, having been created from another work of origin. The research also studies other works that belong to the space of solitude. Resultants created in another format, aiming to graph the crossing of the time space itself. To reflect on the autonomous work derived from another composition, the Freusa Zechmeister's spherical work Triz was chosen, exhibited at the Brazilian Representation of the Prague Quadrennial 2015 Everything to Start Over.

Keywords

Art. Performance design. Model. PQ 2015. Freusa Zechmeister. Corpo Dance Group. 


\section{Tudo por recomeçar ${ }^{1}$}

Não olhar o passado como algo a ser recuperado como força original, como verdade ao pé da letra, mas quer capturar o movimento contínuo da descontinuidade, o turbilhão de imagens que se sobrepõem, (...) de coisas que se desfizeram, destruíram, enterraram. Mas estão lá, aí, aqui: trabalhando, olhando para nós, provocando nossa reflexão. Tudo por recomeçar. Edson Rosa da Silva (SILVA, 2008, p. 309).

Em 2014 fui convidada pelo cenógrafo Ronald Teixeira para integrar a equipe curatorial da Representação Brasileira para a $13^{a}$ Quadrienal de Praga 2015: Espaço e Design Cênico² - PQ'15.

Para a edição de 2015, a Quadrienal de Praga $^{3}$ propunha a reflexão sobre as noções de SharedSpace: Music Weather Politics, lido por nós da equipe curatorial brasileira, como EspaçoCompartilhado: Sonoridade Atmosfera Políticas.

O projeto curatorial para a Mostra Países e Regiões tinha, como ponto de partida, explorar a existência de um espaço singular, habitado pelo designer da cena, previamente à criação da obra cênica.

Vislumbrávamos que a identificação do espaço prévio ao nascimento da ideia projetual pudesse ser revelada a partir do compartilhamento

10 texto é parte integrante da minha atual pesquisa de pós-doutoramento Grafismos na solidão, desenvolvida na Faculdade de Arquitetura da Universidade de Lisboa. $O$ assunto nuclear no qual agora me debruço, passa por identificar o locus solus, entendido como espaço utópico construído solitariamente para que possamos nos dedicar a sonhar com a criação da obra concentrada em seu próprio processo criativo.

2 O cenógrafo Ronald Teixeira foi o Curador da Representação Brasileira. Exerci a Co-Curadoria, fui autora da ideia para a Proposta Curatorial, além de projetar a expografia. Rosane Muniz também integrava o núcleo da equipe como Co-curadora.

3 Ver em: https://www.pq.cz/publications/; http://2015.pq.cz. s3.amazonaws.com/www/en/program/intro.html; https:// quadrienaldepraga.wordpress.com/equipe-brasileira/ . da confissão criadora ${ }^{4}$ do artista. A exploração do subjetivo lugar ocupado por cada artista no ato da criação nasceria das declarações obtidas por meio de entrevistas, a partir das quais, desvendaríamos os seus processos criativos.

A proposição curatorial solicitava ao artista revisitar um trabalho por ele projetado anteriormente, com a intenção de rever o instante do start criativo; refazendo o seu processo de criação até a concepção da resultante projetual cênica. Possibilitando, a partir do retorno à própria obra, transgredir a ideia originária para propor outro caminho a ser realizado através da criação de uma obra original.

Planejávamos, com a proposta, desvendar a 'cenografia invisível'5 anterior ao projeto posto em cena. Cenografia, nesse caso, é entendida como espaço idealizado e utópico.

Ao tornar visível a percepção dos espaços subjetivos dos criadores da cena, o agrupamento das obras inéditas projetava a fundação de um campo-paisagem $^{6}$, igualmente, coabitado pelo visitante-observador.

Pretendíamos, a partir do conceito da ex-

4 O ensaio "Confissão criadora" (KLEE, 2001, p.43-50) foi originalmente publicado em 1920 para o volume de coletânea Tribüne der Kunst und Zeit, organizado por Kasimir Edschimid que "havia pedido a vários artistas plásticos, escritores e músicos que escrevessem algo acerca da própria atividade artística", como Günther Regel expõe em "Notas" (KLEE, 2001, p.122) do livro Sobre a arte moderna e outros ensaios, onde o artigo é reproduzido.

5 Sodja Lotker, Curadora da PQ'15, expõe na Proposta Curatorial a sua esperança em revisitar o teatral - o imaginário, o visionário, e o inexistente como poder sócio-político criativo. Pretendendo ainda, descobrir a cenográfica invisível como aquelas que nos influencia profundamente, embora intangíveis. Ver em: https://www.pq.cz/publications/.

$6 \mathrm{O}$ conceito de paisagem ao qual me amparo surge da possibilidade de existência de uma frágil brecha traçada por uma aparente contradição, a relação entre a delicadeza e o desamparo. A ideia projetada por Hirsch é apresentada por Denílson Lopes no texto Invisibilidade e desaparecimento. Lopes traça, ainda, o amálgama existente na convivência entre a materialidade do cotidiano e a leveza do devaneio. "A paisagem mais do que um estilo de pensar e escrever, é uma forma de viver à deriva, entre o banal e o sublime, a materialidade do cotidiano e a leveza do devaneio". (HIRSCH, 1995 apud LOPES, 2008. p. 84). 
pografia, a instauração de uma arena pluridimensional na qual a multiplicidade de olhares coabitasse um vivo território cinético.

Esperávamos, dessa forma, tornar visível a percepção dos espaços particulares que atuam como campo de força quando reunidos, e uma vez compostos em superposição fundam a paisagem. Planejando, desse modo, cartografar os cinéticos territórios da criação.

A Proposta Curatorial da Representação Brasileira para a Mostra Países e Regiões da Quadrienal de Praga de 2015 recebeu o título Tudo por Recomeçar e o projeto expográfico adotava o conceito de cenografia como o lugar do espectador, desenvolvido na tese $A$ cenografia além do espaço e do tempo. O Teatro de dimensões adicionais $^{7}$ (ROLLEMBERG, 2008), que defendi em 2008. Desde 2011, estudo possíveis materializações dos conceitos investigados na pesquisa. Concretizando em obra, potenciais grafias para esquematizar as dimensões adicionais do espaço.

Envolvido com as mesmas intenções que motivaram a criação da maquete-objeto Grafismos que apresentei na Mostra World Stage Design 2013, o projeto do dispositivo expográfico para Tudo por Recomeçar, igualmente, objetivava investigar possibilidades de grafias do movimento. Materializando em obra, a esquematização do tempo.

Nesse sentido, o projeto recompõe os princípios comuns desenvolvidos em Grafismos, e pode ser registrado como o segundo exercício executado, em outra escala, e em outro formato, para a concretização das mesmas ideias aplicadas na maquete-objeto, anteriormente por mim projetada.

\section{Grafismos}

Figura 1 - a,b,c (peep hole), d,e,f (visão interior da maquete-objeto): Grafismos - World Stage Design 2013, Cardiff.v
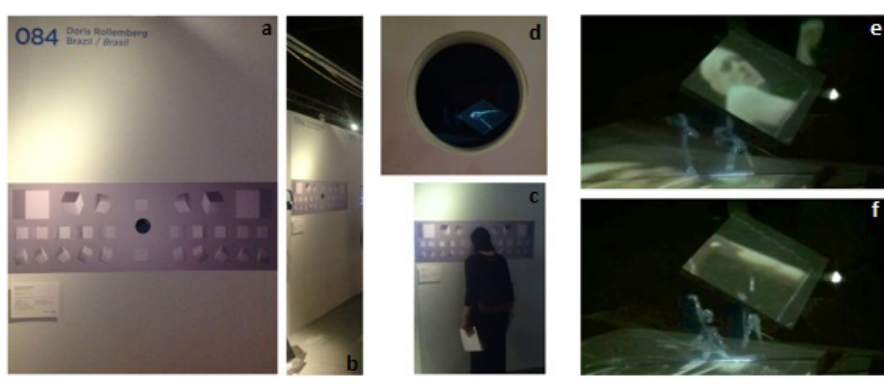

Fonte: Fotos de Renato Silva.

Diferentemente do que havia proposto na criação da obra Grafismos, em Tudo por Recomeçar o observador não é fixo, e nem tão pouco solitário. Além da existência dos múltiplos pontos de vistas habitando concomitante o espaço-paisagem, cada observador precisa se deslocar pelo espaço. Indo além, para visualizar o interior das obras, precisa movê-las verticalmente. A observação é feita, igualmente, através de um peep hole, como havia realizado em Grafismos.

A grafia do espaço temporal de Tudo por Recomeçar (figura 2 - a, b,c,d,e) é traçada pelos vetores óticos dos múltiplos olhares existentes dentro, e também situados fora do dispositivo instalativo. Somados, ainda, aos diversos vetores de movimento dos observadores, em seus deslocamentos no espaço, e nas ações desempenhadas para os deslizamentos verticais das obras esféricas.
7 Tese defendida em 2008 no Programa de Pós-graduação em Artes Cênicas da Universidade Federal do Estado do Rio de Janeiro com a orientação da Professora Doutora Lídia Kosovski. 


\section{Representação Brasileira na Quadrienal de Praga 2015}

Figura 2 - Espaço expográfico brasileiro na Mostra dos Países e Regiões, da Quadrienal de Praga 2015.
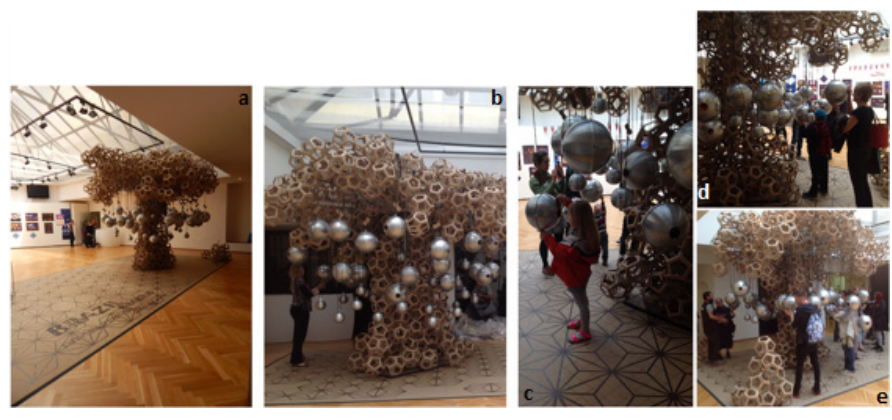

Fonte: Fotos de Renato Silva.

O espaço expográfico concretiza, em escala bem distinta da miniaturização proposta por Grafismos, um complexo mapa constituído por vetores, por linhas, por fluxos, por tensões e por sentidos, redesenhados por sobreposição infinitas vezes.

Nesse caso, a escala do dispositivo expográfico está mais próxima da relação direta com a figura humana. A paisagem Ihe é 'familiar', e o ativo observador ocupa, e domina a cenografia, deslocando-se para se conectar com o duplo espaço. Tornando-se voluntariamente, em alguma instância, o ator da cena.

A duplicidade espaço temporal existe na convivência das duas obras em escalas e em formatos distintos que coexistem na "paisagem". As 'verdadeiras' obras, do mesmo modo, assim como na maquete Grafismos, estão inscritas em um diminuto espaço.

Aobra inseridano interior de uma esféricametálica de 0.32 de diâmetro em Tudo por Recomeçar configura, assim como em Grafismos, um peep box, dentro do qual habita uma maquete, ou uma obra miniaturizada.

O interior das esferas abriga as obras originais, especialmente compostas para a Mostra Países e Regiões da Representação Brasileira da Quadrienal de Praga 2015. Na tampa do peep hole, que oculta a visão do interior da esfera, há a foto com a imagem da obra que deu origem ao trabalho inédito.
Em Grafismos a relação do observador com obra é intima, resultante da visualização 'segredada', semelhante à sensação de estarmos sós, de sermos os únicos no espaço de observação, podendo, solitariamente, cruzar o buraco de minhoca ${ }^{8}$ para realizar o atravessamento de planos paralelos. Enquanto em Tudo por Recomeçar a percepção é de não estarmos sozinhos. O espaço é compartilhado, mas a despeito dessa condição, é possível experimentar a sensação de solidão. Podemos através do nosso olhar entrar isoladamente nos diversos espaços temporais reveladores da memória recuperada, revista, ou ainda recriada. Imagens que reconfiguram o tempo.

Foram convidados 29 designers da performance de diferentes gerações, e de várias regiões do Brasil para a produção dos trabalhos apresentados na Mostra Países e Regiões (MUNIZ, 2015).

A proposição curatorial apresentada aos artistas se origina a partir do mesmo princípio fundamental desenvolvido para a criação da maquete-obra Grafismos. De modo análogo, a obra original deveria ser projetada a partir da revisitação do processo criativo para um projeto de encenação anteriormente por eles realizado.

A proposta ressaltava que a concepção da obra derivativa não seria a memória do projeto realizado previamente. A criação inédita deveria ser traçada como se fosse um movimento contínuo de descontinuidade, assumindo a ideia do nosso "eterno começo". Assim, 'chegar' à obra originária com o olhar da primeira vez.

As obras especialmente criadas para a Representação Brasileira na PQ'15 compõe uma importante coleção inédita, reunindo nomes de excelência da cena contemporânea brasileira.

Um elenco de notáveis revisitando as suas próprias obras, refazendo os seus processos de criação, escavando memórias, se instrumentalizando para a composição da esfera como obra independente e original.

8 Buraco de minhoca conecta duas regiões que existem em períodos diferentes de tempo. O buraco de minhoca pode ligar o presente ao passado e vice-versa. (KAKU, 2000, p. 36-44). 
Talvez muitos desses artistas tenham tido a experiência de retornar a um projeto anteriormente por eles projetado para fazê-lo outro, ou pelo menos para realizá-lo em outro formato, pela primeira vez. Observa-se que, ao menos, o formato esférico não é usualmente utilizado como suporte à obra. $O$ cubo é o nosso constante 'abrigo'. Mesmo quando não estamos inseridos na caixa cênica à italiana. Mesmo quando não queremos estar limitados e enquadrados para a criação cênica. Mesmo quando gostaríamos de propor outras formas mais participativas ou inclusivas na relação da cena com o espectador.

Nesse sentido, criar para o interior de um pequeno espaço esférico metálico, inclusive um pouco espelhado, reflexivo em duplo sentido; somado a ideia da visualização da obra ser realizada através de um diminuto buraco; e ainda propondo outro tipo de relacionamento com o observador, é ocupar uma posição singular.

Ainda cabe destacar que a criação autorreferente requer, a princípio, a edificação de um mundo utópico que propicie à autorreflexão. Espaço idealizado solitariamente ${ }^{9}$, para a criação destituída do objetivo concreto da obra projetada para a cena. Somente habitando esse subjetivo espaço parece ser possível sonhar com a criação da obra concentrada em seu próprio processo criativo. E a partir desse 'lugar' rever, ver e fazer ver, para que todos possam visualizar os espaços subjetivos do seu processo de criação.

É necessário muitos outros atributos com os quais se equipar, estando disposto a partir para buscar o mistério da própria criação, e dessa forma, reencontrar o seu espaço em algum lugar do seu deslocamento.

É importante, antes de tudo, munir-se da alegria para 'chegar' ao ponto de partida, revendo as ideias originárias do processo de criação; deixando-se repossuir pelo fluxo do pensamento criativo como se esse ainda estive pulsante, ou ao menos, tentar recu-

9 Mesmo quando o artista selecionado para participar da Mostra Países e Regiões da Quadrienal de Praga de 2015 tinha, na encenação selecionada pela equipe curatorial, realizado o trabalho de forma colaborativa, a proposição indicava que a criação inédita deveria ser concebida solitariamente. perar o nascimento da ideia, disposto a recompor e ir além, para ousadamente ser outro sendo o mesmo.

A Mostra Tudo por Recomeçar não foi exposta no Brasil. Por inúmeras razões, apresentar, ou estudar esse acervo seria necessário e relevante. Além do rol de importantes nomes do design cênico envolvidos, que por si só qualifica e justifica o estudo, as esferas inéditas são obras autônomas que merecem ser estudadas. As esferas são obras resultantes do deslocamento do campo primeiro de atuação do seu criador para a composição de um objeto independente, não relacionado à concretização da obra projetada para uma encenação futura.

As obras esféricas representam um belo fragmento do movimento espaço temporal e se tornam propostas representativas dos deslocamentos das trajetórias de cada artista, e do mesmo modo, se configuram como obras inéditas que se tornam autônomas.

Recompor esse acervo é, ao mesmo tempo, possuir e ser possuído por essas obras como objetos de desejo. Se não faço agora essa retomada de maneira mais ampla, tendo apenas selecionado a obra esférica Triz de Freusa Zechmeister, posso me alegrar por possuir, e me deixar repossuir por esse acervo ainda a ser processado, estudado. Poderei retomar à coleção como meio de locomoção para atravessamentos futuros, munida das mesmas ideias e repetições. Assim, guardo esse conjunto para fitá-lo posteriormente, certa que estou de que já fui por ele iluminada.

Será um modo de percorrer o meu processo criativo, desenvolvendo diálogos na solidão.

\section{- Triz - A grafia da espada do tempo}

Para sempre é sempre por um triz. Chico Buarque ${ }^{10}$.

Triz da figurinista e arquiteta Freusa Zechmeister é a obra esférica que escolho entre os 29 trabalhos originais expostos na Mostra dos Países e Regiões da Representação Brasileira

10 Frase extraída da música Beatriz, de Chico Buarque de Holanda. 
na quadrienal de Praga 2015 (PQ'15), para pensar sobre a obra que se torna autônoma, tendo sido criada como um derivativo de uma produção anteriormente realizada em outro formato.

Exploroaobrainéditaconcebidaapartirdaideiade retomada do seu processo de criação para uma produção artística anteriormente realizada, a obra originária.

O objetivo da proposta curatorial não era trabalhar como algo a ser recuperado. Ao contrário, a proposta solicitava ao designer da cena estar disponível a capturar "o movimento da descontinuidade, o turbilhão de imagens que se sobrepõem, (...) de coisas que se desfizeram, se destruíram, enterraram. Mas estão lá, aí, aqui: trabalhando, olhando para nós, provocando nossa reflexão" (SILVA, 2008).

Freusa Zechmeister grafa, em uma resultante poética e ousada, a impiedosa espada do tempo. A obra esférica se impõe, ainda, pela cáustica ausência de luz. Sua proposta para a esfera prossegue com o mesmo pensamento sintético, dotado de certa ironia crítica, presente nos figurinos da obra originária.

Triz, a obra esférica, relê, ou mais correto seria dizer, se faz uma obra outra, ao revisitar os figurinos criados por ela para a performance de dança Triz do Grupo Corpo ${ }^{11}$.

\section{Triz - Grupo Corpo}

Figura 3 - Fotos de cena. Triz, 2013.
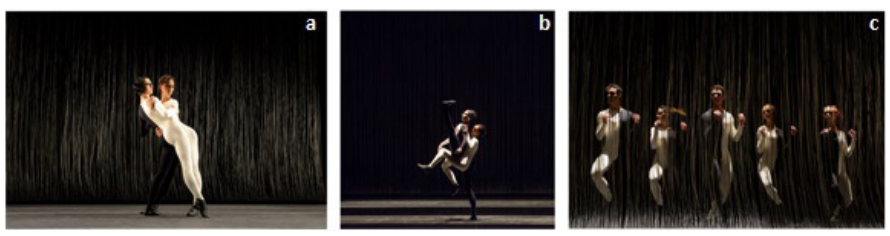

Fonte: Fotos de José Luiz Pederneiras. Ver no site do Grupo Corpo em:

< http://www.grupocorpo.com.br/pt-br/obras/19/triz >.

11 Trizestreou no Palácio dasArtes, Belo Horizonteem 2013. Grupo Corpo: Paulo Pederneiras (autor, diretor e cenógrafo), Rodrigo Pederneiras (coreógrafo), Freusa Zechmeister (figurinos) Paulo Pederneiras, Gabriel Pederneiras (iluminadores) e José Luiz Pederneiras (fotógrafo) com músicas especialmente compostas por Lenine (diretor musical).
Freusa captura o movimento inicial do seu processo de criação, como se esse pensamento ainda estivesse em andamento contínuo. Desenterra o mote central da proposta conceitual de Triz, para realizar uma potente obra síntese. Não apenas pela resultante formal que habita na esfera, mas, sobretudo porque Freusa capta, de modo certeiro, a proposta curatorial brasileira para a PQ'15. Ela caminha em direção ao ponto nuclear da proposição curatorial, aproximando-se igualmente, em ferina concretude, das questões com as quais o Grupo Corpo se ocupava no período de conceituação para a montagem de Triz ${ }^{12}$.

Freusa desenvolve, com a obra esférica, uma resposta pungente e inspirada, não apenas para si mesma, ao retornar ao processo criativo da sua obra originária, mas, sobretudo ao propor uma resultante mordaz, que apreende de modo veemente à proposição curatorial. Duplo alvo, resposta única.

\section{Triz - Freusa Zechmeister}

Figura 4 - Obra esférica Triz 2015.
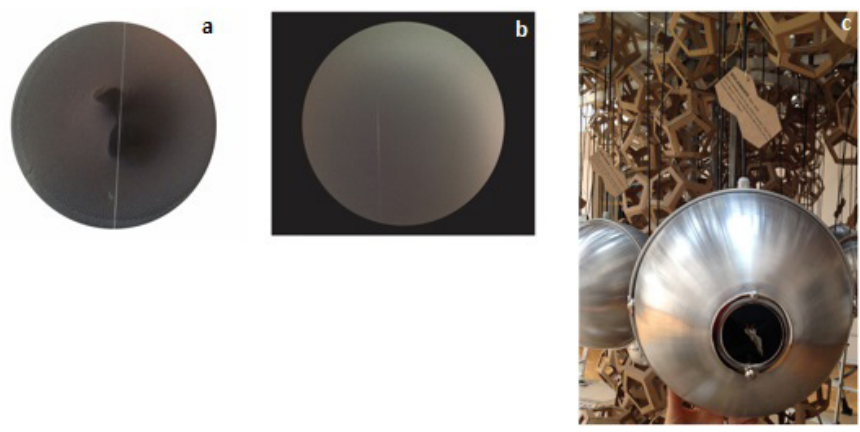

Fonte: Fotos de Renato Silva $(a, b)$ e Rosane Muniz (c).

Como anteriormente mencionado, a ideia para a criação da obra original não tinha como proposta a repetição ou a representação do projeto, ou ainda a miniaturização da obra originária. Propunha ir além. $A$ esfera deveria ser criada a partir da noção do "eterno começo" existente nos processos criativos. Deveria

12 A limitação de tempo para produção da obra coreográfica foi acarretada pela mobilidade comprometida do coreógrafo Rodrigo Pederneiras que havia se submetido a uma cirurgia no joelho. 
ser projetada se valendo da ideia que a reflexão para a criação de uma obra jamais se esgota na própria obra.

E por essa perspectiva, a proposição permitiria repensar a si mesmo, refazendo-se para a concepção da obra esférica original. Até porque, o formato do espaço esférico; a sua diminuta dimensão ( $\varnothing$ 0.32), e a maneira como o interior da esfera seria visualizado pelo observador já propunham em si mesmo a noção de refazer o caminho de outra forma.

Assim sendo, a proposição curatorial pretendia pensar sobre outras formas para grafar as mesmas ideias, projetando outros traços em função do que existia anteriormente, e que ainda permanecem povoando o nosso pensamento.

Freusa se abre a essa proposta com inegável e sincera entrega. Revelando uma atitude generosa, apropriando-se desses conceitos corajosamente.

Desse modo, ela passa a pertencer ao lugar predeterminado pela curadoria, habitando esse espaço, não apenas por seu entendimento e sua aceitação, mas, sobretudo por estar repleta dos sentimentos de pertencimento e de reconhecimento.

Freusa revê o seu prévio lugar de criação, e transportada para esse outro espaço idealizado, reafirma o seu papel de autoralidade, e o seu território de autoridade.

Freusa volta ao seu idealizado locus solus para projetar a esfera com o alegre olhar da primeira vez. E ainda, nos permite 'ouvir' a sua bela e ousada confissão criadora, através da sua obra esférica Triz. Uma resultante imagem síntese capaz de nos revelar o prévio lugar idealmente habitado por ela para criar os figurinos de Triz.

É interessante observar que a criação da obra inédita não é pensada a partir do sentimento de preenchimento de uma lacuna que permaneceu sem solução na criação anterior. Ao contrário, a proposta da esfera Triz reafirma, de modo contundente, que voltar a primeira ideia, ou a questão central que alimentou o processo de criação pode confirmar a continuação da nossa ida, da nossa trajetória. $O$ traçado inicial continua a ser desenhado continuamente em outras possibilidades ou formatos.
Freusa volta ao conceito-chave, retoma a ideia mestra da proposição do Grupo Corpo para a performance Triz para produzir a imagem síntese de um fio tensionado no interior da esfera forrada por uma malha escura como as utilizadas na meia calça, propositalmente um espaço sem luz.

Freusa Zechmeister refaz o instante do start criativo, fazendo que todos vejam o nascimento da ideia. Modo confesso e direto para que possamos visualizar os espaços subjetivos existentes no processo de criação. Dar a ver o locus solus comumente não revelados.

\section{Por um triz}

Por um triz é uma expressão vocabular que imediatamente se impõe como imagem de um traçado vetorial, que traz em si, simultaneamente perigos e desafios.

Não poderia ser também a mesma sensação experimentada pelos artistas em algumas etapas do processo de criação?

Estar por um triz, por um fio de cabelo, estar no sutil limite daquilo que pode se romper a qualquer momento, causando medo, e revelando o constante risco.

Por um fio, igualmente pode representar o traço inicial, a primeira linha do esboço que antevê a obra. A grafia do desenho que assume o risco, e o desafio da criação.

A imagem do fio tensionado prestes a se romper, cena originária de uma história mitológica, representa a circunstância pela qual o Grupo Corpo se encontrava no momento do processo de produção da performance Triz. A veemente espada pendurada por um fio sob suas cabeças, pronto a se romper por um triz.

A sensação de estar sob a mira da mitológica espada de Dâmocles, suspensa por um tênue fio de crina de cavalo, foi tão imperativa durante todo o período de gestação deste balé do Grupo Corpo que acabou não apenas se impondo como o grande mote para a sua criação, mas servindo, também, de inspiração para o seu nome - Triz, palavra de sonoridade onomatopaica, que tem nos vocábulos gregos triks/trikós (pelo, cabelo) sua mais provável origem etimológica, simbolizada pela expressão por um triz (por um fio). 
(ALMEIDA, 2013. Documento eletrônico) $)^{13}$.

A espada suspensa por um fio de crina de cavalo que pairava sobre Dâmocles ${ }^{14}$ é o espelhamento da situação vivida pelo grupo.

Circunstância imposta, não apenas pela limitação de tempo para a criação da performance de dança, mas sobretudo porque essa ideia representa, do mesmo modo, o lugar de desafio e de risco alcançado pelo Grupo Corpo ao longo da sua vitoriosa trajetória internacional. O grupo chegou a um patamar profissional no qual o tênue fio da espada está sempre apontado para eles, por um triz. A imagem retrata o risco pelo qual passam aqueles que chegam a esse lugar de notoriedade onde os pagantes exigem o bis.

A vida da atriz Se ela um dia despencar do céu $\mathrm{E}$ se os pagantes exigirem bis. Chico Buarque ${ }^{15}$.

O Grupo Corpo esteve por um triz, entretanto o perigo eminente do rompimento do tênue fio resultou em uma potente performance.

Por não poder demonstrar as frases coreográficas para os bailarinos com o seu próprio corpo, no início do processo, Rodrigo Pederneira 'cria' outras formas de se comunicar com seus intérpretes ${ }^{16}$.

O mesmo faz Freusa com o desafio da obra esférica, ela se vale de outra expressão artística para comunicar o seu lugar de criação. Ela não reproduz os desenhos dos figurinos, ela não se ampara sequer, na proposta para a esfera, na representação da

13 Trecho retirado do texto de Angela de Almeida, escrito em agosto de 2013, para o release de Triz. Ver no site do Grupo Corpo em: < http://www.grupocorpo.com.br/ uploads/release-ptbr/VaxkMkppc1ZcUZu4fUH7tatdWJ1ZIA58wvZv7ad6.pdf >.

14 Ver em: < https://pt.wikipedia.org/wiki/D\%C3\%A2mocles $>$.

15 Trecho extraído da música Beatriz, de Chico Buarque de Holanda.

16 Ver o documentário Por um triz. Direção: Eduardo Zunza/ Produção e realização: Camisa Listrada / Coprodução: Quarteto Filmes/ Correalização: Grupo Corpo. figura humana, para quem projeta os seus figurinos.

Freusa produz uma obra escultórica na qual o corpo, matéria primeira para a sua criação está ausente. Ela cria um espaço vazio, onde as ausências da luz e da figura humana traduzem de forma potente o eminente risco. O desafio da criação da obra originária Triz é transferido para a obra esférica.

$O$ fio tensionado prestes a ser romper que esteve presente no espaço da criação do processo originário, agora habita a obra esférica. Freusa assume o risco, gosta da provocação, e se declara autoral.

O espaço escuro visto através do peep hole se torna ainda mais perigoso e instigante. $O$ fio verticalizado é visualizado, e nos remete a percepção de tensão.

Freusa compõe com a obra-esférica Triz uma brecha sutil escavada entre a delicadeza da alegria e o desamparo do risco. Com a obra, Freusa assume belamente o devaneio da sua imaginação-criação.

A obra nos reeduca para a delicadeza, afirmando ainda, que há alegria proveniente do desafio e que "é perigoso a gente ser feliz".

Sim, me leva pra sempre, Beatriz Me ensina a não andar com os pés no chão

Para sempre é sempre por um triz Aí, diz quantos desastres tem na minha mão Diz se é perigoso a gente ser feliz. Chico Buarque ${ }^{17}$.

Freusa Zechmeister, em depoimento à pesquisadora Rosane Muniz para o catálogo da mostra Tudo por Recomeçar, revela que aceitou o desafio de criar a obra esférica inédita, a partir da obra de origem em razão da curadoria ter escolhido Triz. Confidenciando: "Me deu a sensação de prazer. Perceber o que nem eu saberia dizer. Achei instigante." (MUNIZ, 2015, p. 72).

A vitoriosa veterana artista se sente instigada ao 'perceber' que não 'saberia dizer', ou ainda, perceber que teria que 'dizer' de outra maneira, em outro contexto e em outro formato. O prazer e a alegria pelo risco.

Por essa ótica, Freusa produz a obra, inicialmente, como 'diálogo' consigo mesma. Mas igual-

17 Trecho extraído da música Beatriz de Chico Buarque de Holanda. 
mente, a esfera é criada como um exercício de comunicação capaz de permitir ser percebida por todos.

Assim, a esfera é criada a partir de um duplo espaço idealizado que se interceptam. O espaço prévio à criação, o locus solus habitado pela Freusa Zechmeister, e o espaço de criação proposto pela Curadoria brasileira para a PQ'15 que ela se permite visitar.

Portanto, a esfera Triz pertence a um duplo lugar idealmente projetado como o lugar propício à reflexão do que ela não 'saberia dizer'. Um "campo" fértil de delicadezas.

\section{- A obra esférica se torna autônoma, tendo sido criada como um derivativo de uma produção realizada anteriormente em outro formato}

No primeiro ensaio vi uma floresta com linhas, (...) uma movimentação em que tudo se misturava. (...) Amo preto e branco, é cor e não é cor, e como não via cor na imagem, provoco a sensação da combinação dos bailarinos ao parecer que um ser está colado ao outro. As malhas inteiriças e os corpos seccionados em duas metades, verticais e simétricas, leva às raias a brincadeira em torno da relatividade do limite e cria uma série de duos femininos. Crio figurino igual a um espaço arquitetônico, e lido com os bailarinos como se fosse um objeto em movimento. Começo a trabalhar com o olho, depois é que preciso da música. Ao desenhar os pontos iniciais de ocupação ou não do espaço, a movimentação cênica me dá uma forma ou uma cor. Ao revisitar essa criação, me lembro do jogo de espelhos. Queria ser Escher! Gosto mais de ver galerias, obras de arte, do que arquitetura. As Artes Plásticas me liberam. Posso tudo! Dá liberdade e começo a criar outras coisas... Aceitei participar desta exposição por terem escolhido Triz. Me deu a sensação de prazer. Perceber o que nem eu saberia dizer. Achei instigante. (ZECHMEISTER, 2015) ${ }^{18}$.

Freusa Zechmeister é arquiteta. É muito interessante descobrir que o seu processo de criação tem início a partir do pensamento para o espaço da

$18 \mathrm{Em}$ entrevista a Rosane Muniz para o catálogo Tudo por Recomeçar (MUNIZ, 2015). cena. Nesse caso, para o espaço prontamente cenografado. Freusa visualizou primeiramente uma floresta de fios, por onde os bailarinos se movimentariam.

O ponto de partida para a sua criação parte, portanto, da noção do espaço rítmico, ou seja, do espaço temporal. As dimensões adicionais do espaço se encontram no berço do seu processo criativo.

A floresta de linhas visualizada antecipadamente por Freusa, como o espaço para a cena, possibilita que a figura humana, por ela tratada como objetos em deslocamentos, se deslocassem como se estivessem atravessando diferentes planos paralelos, perpassando mundos conectados por espelhos.

Meu sonho de consumo é ser uma física para criar na esfera uma sabedoria com jogo de espelhos pra criar no figurino a sensação da dualidade. O branco não é nada. O preto não é nada. Queria provocar nesta revisita a sensação da combinação deles, se mostra, não mostra. A iluminação do Paulo ajudou a criar este duo no espetáculo, fazendo o preto desaparecer, faz parecer que um ser está colado ao outro. Crio figurino igual a criar um espaço arquitetônico. Minha intenção de criar os objetos no espaço veio do desejo de criar um que são dois em um. Sensação de que é um branco, de que é um preto, mas de repente vem a ideia de que são dois em um. Cada balé tem um ou dois momentos de prazer. Em Triz, este momento, pra mim, acontece quando um bailarino vem numa posição, quando chega a outra posição está de outro jeito, segue... Vai, e vai, brinca... E muda o figurino pra permitir que todos estivessem com o mesmo lado. (ZECHMEISTER, 2015) ${ }^{19}$.

A ausência de cor, imaginada por Freusa desde o momento inicial do processo, se materializa na criação dos figurinos em preto e branco/metade-metade.

A metade preta das malhas usadas pelos bailarinos, ou parte dessa massa preta, muitas vezes desparece na sua relação com o espaço da cena. Criando a ilusão de estarmos diante de seres híbridos.

19 Em entrevista a Rosane Muniz para o catálogo Tudo por Recomeçar (MUNIZ, 2015). 
Pernas ou braços cobertos pelas partes em preto do figurino, ora se ausentam dos nossos olhos, ora se unem às outras partes dos corpos de outro bailarino formando corpos outros, estranhamente belos.

Para João Paulo (2013), em crítica à montagem de Triz, o figurino "segmentado longitudinalmente, 'dividindo' o bailarino ao meio e criando, com o movimento, a ilusão de novos seres mitológicos paridos pelo movimento." ${ }^{20}$.

A cenografia de Paulo Pederneiras, uma floresta de cabos de aço tensionados, fecha o espaço cúbico em três lados em formato de U. Algumas aberturas existentes nessa composição permitem a entrada e a saída dos intérpretes. O dispositivo cênico se comporta como um ciclorama, e ainda, permite a projeção de sombras no chão do palco, nos fundos situados atrás dos alinhamentos dos cabos, e também por rebatimentos de sombras de uma estrutura de fios sobre outra 'parede' de cabos. O próprio material e a forma como esses cabos de aço estão instalados permitem o atravessamento de luzes entre as cortinas de fios.

Linhas, ou cabos que respondem formalmente aos desafios e às tensões vividos pelo Grupo Corpo. Fios que não parecem estar prestes a se romper, seguros que estão pela concretude poética das suas obras.

A cenografia e o figurino constroem jogos de espelho. Propondo imagens espelhadas por rebatimento (das 'paredes' e dos corpos); por figuras partidas que ocultam parte do todo, dependendo de como se posicione diante do 'espelho', e pelas resultantes de corpos estranhos, como se estivessem diante de espelhos retorcidos.

O espelhamento do dispositivo cênico também pode ser reconhecido como "buracos de minhoca" que conduzem ao atravessamento de mundos paralelos. Hiperespaço no qual habitam figuras híbridas. Segundo Freusa, as 'artes plástica pode tudo'. Sabemos que a dança também.

20 Publicado por João Paulo em 02 de Setembro de 2013. Disponível em: < https://www.uai.com.br/app/noticia/e-mais/2013/09/02/noticia-e-mais, 145914/grupo-corpo-surpreende-com-triz.shtml >. Acesso em: 15 set. 2019. (PAULO, 2013).
Freusa queria 'ser Escher' para ter a capacidade de criar planos que não seriam possíveis, projetar estruturas imprevisíveis. Fazer ver o impossível.

Os bailarinos em Triz têm os seus olhos grifados por uma maquiagem que delimita um estreito retângulo, como se quisesse marcar o olhar da figurinista que antecipa a presença da música no início do seu processo de criação. Desse modo, os interpretes, 'objetos em movimento no espaço', atuam como se estivessem reafirmando o ponto de vista de Freusa Zechmeister. Triz se constitui como obra que grafa o espaço-tempo.

A obra esférica Triz, igualmente, grafa o tempo. Nesse caso, a grafia do tempo pode ser compreendida por duas instâncias. A primeira entrada que confirma a tese é observada a partir da importância que a noção de espaço temporal é revelada como o detonador do processo de criação de Freusa Zechmeister. A segunda via mais explícita é identificada na resultante formal da obra esférica que traz, de forma direta, o tênue fio que tenciona a cruel espada do tempo.

Triz, a obra originária e a derivativa obra esférica vencem o tempo. O impiedoso tempo perde o jogo, não conseguindo, dessa vez, arrancar pedaços substantivos do todo. Porém, se o tempo aqui não consegue fazer com que a poesia se encontre na incompletude, no que falta à obra, ele é hábil em ativar a poesia de outro modo. Ela está presente ao jogo onde todos ganham, vivenciando uma obra afiada como a espada suspensa por um fio, prestes a se romper, o que não nos deixaria ver o "rosto do deus olímpico".

Freusa tinha conseguido 'ser Escher' com a criação dos figurinos de Triz. A malha metade-metade em preto e branco é uma clara proposta de grafismos de estruturas impossíveis que possibilitam ilusões de ótica.

A bidimensionalidade da 'cor' cheia veste a tridimensionalidade dos corpos que se movimentam na tetradimensionalidade do espaço. Dessa forma, a concepção dos figurinos se revela como um exemplo de sucesso para o estudo de ritmo em padrões geométricos. Mundos de dimensões adicionais, como os vistos em Escher. 
Tal como Escher, Freusa trabalha com os conceitos de espelhamento, de rotação, de isometria, acrescentando movimentos de translação à forma, e desse modo, ela desconstrói a previsibilidade, propondo a ilusão de estarmos diante de novas formas humanas. Outros corpos improváveis.

O positivo e o negativo, tão característicos na obra de Escher, são utilizados por Freusa, ora destacando a figura do fundo, ora nos confundindo com a criação de suas improváveis e impossíveis estruturas corpóreas.

Freusa acolhe a criação da obra inédita a partir do pensamento circular, ou infinito, como a fita de Moebius, também vista em Escher. Ela retoma o processo de criação de Triz, como se estivesse em um percurso contínuo para a concepção da obra esférica.

Freusa Zechmeister é Escher.

\section{Referências}

ALMEIDA, Angela de. Release de Triz. Disponível no site do Grupo Corpo em: < http://www. grupocorpo.com.br/pt-br/obras/19/triz >. 2013.

KAKU, Michio. Hiperespaço: uma odisséia científica através de universos paralelos, empenamentos do tempo e a décima dimensão. Tradução de Maria Luiza X. de A. Borges. Revisão técnica de Walter Maciel. Rio de Janeiro, Rocco, 2000.

KLEE, Paul. Sobre a arte moderna e outros ensaios. Rio de Janeiro, Jorge Zahar Editor, 2001.

LOPES, Denílson. Invisibilidade e desaparecimento. In: Espécies de Espaços: territorialidades, literatura, mídia. Organizadores: Izabel Margato e Renato Cordeiro Gomes. Belo Horizonte. Editora UFMG, 2008.

MUNIZ, Rosane (Org.). Brasil: Tudo por recomeçar. Quadrienal de Praga: Espaço e design da performance 2015. Everything to start over. Rio de Janeiro, FUNARTE, 2015.
PAULO, João. Grupo Corpo surpreende com Triz. Uai, 2013. Disponível em: < https://www. uai.com.br/app/noticia/e-ais/2013/09/02/noticia-e-mais, 145914/grupo-corpo-surpreende-com-triz.shtml >. Acesso em: 15 set. 2019.

ROLLEMBERG, Doris Cruz. A cenografia além do espaço e do tempo. O Teatro de dimensões adicionais. 2008. (Tese) Doutorado em Teatro. UNIRIO. Rio de Janeiro, 2008.

SILVA, Edson Rosa da. Inventário e imaginação. In: MARGATO, Izabel; GOMES, Renato Cordeiro (Orgs.). Espécies de Espaços: territorialidades, literatura, mídia. Belo Horizonte. Editora UFMG, 2008.

ZECHMEISTER, Freusa. Entrevista concedida a Rosane Muniz para o catálogo Tudo por Recomeçar. In: MUNIZ, Rosane (Org.). Brasil: Tudo por recomeçar. Quadrienal de Praga: Espaço e design da performance 2015. Everything to start over. Rio de Janeiro, FUNARTE, 2015.

Recebido: 09/06/2020

Aprovado: 15/07/2020 